This page is intentionally left blank 


\section{Hermann Wimmel}

\section{QUANTUM PHYSICS \& OBSERVED REALITY}

\section{A CRITICAL INTERPRETATION OF QUANTUM MECHANICS}




\section{Published by}

World Scientific Publishing Co. Pte. Ltd.

P O Box 128, Farrer Road, Singapore 9128

USA office: Suite 1B, 1060 Main Street, River Edge, NJ 07661

UK office: 73 Lynton Mead, Totteridge, London N20 8DH

Library of Congress Cataloging-in-Publication data is available.

\section{QUANTUM PHYSICS AND OBSERVED REALITY \\ A CRITICAL INTERPRETATION OF QUANTUM MECHANICS}

Copyright @ 1992 by World Scientific Publishing Co. Pte. Ltd.

All rights reserved. This book, or parts thereof, may not be reproduced in any form or by any means, electronic or mechanical, including photocopying, recording or any information storage and retrieval system now known or to be invented, without written permission from the Publisher.

ISBN $981-02-1010-8$

Printed in Singapore by JBW Printers \& Binders Pte. Ltd. 


\section{Abstract}

The so-called orthodox, or Copenhagen, interpretation of quantum mechanics has paradoxical and illogical features because it fails to analyze the concepts of observation and measurement and, moreover, mixes classical and quantum concepts. The systematically derived interpretation presented here now rectifies these shortcomings and, in particular, avoids the mixing of concepts by using a two-model approach, the models being related to each other by appropriate translation procedures. The primary model, the so-called Model of Facts, or F-model, contains all directly or classically observable factual information of relevance. The secondary model, the so-called $\psi$-model, contains the information given by the quantum formalism and its concepts. The interpretation is based then on ordinary events and other facts rather than on the ill-defined concept of measurement. "Quantum objects proper", however, are exclusively described by the concepts of the quantum formalism, without additional (classical) properties of these objects being introduced. This conceptional restraint is necessary because the appropriate indirect observations critically depend on theoretical inference. The new interpretation leaves the range of application of the formalism unimpaired, except that misconceived and falsely declared applications are sorted out and redefined as pseudo-measurements. The standard measurement axioms are accordingly revised and the new concept of "quasi-measurement" is introduced. Empty concepts, undecidable propositions and questions, as well as paradoxes, e.g. ones connected with wave function "collapse", are avoided throughout. The Copenhagen interpretation is analyzed and refuted. The present interpretation is simple enough to be of practical use, e.g. in tuition and the analysis of quantum physics experiments. 
This page is intentionally left blank 


\section{CONTENTS}

Abstract $\quad v$

I. Introductory Remarks and Exposition 1

A. Preface 1

B. The Copenhagen interpretation 2

C. Ambiguous language 3

D. Intellectual deadlock 5

E. Heuristic considerations $\quad 7$

F. Subject of investigations 9

G. Guides to the literature $\quad 10$

II. Observability and Existence of Properties 11

A. Direct versus indirect observation $\quad 11$

B. "Measurement" 12

C. Copenhagen measurement axioms 16

D. Revised axioms $\quad 17$

$\begin{array}{ll}\text { E. Pseudo-measurements } & 21\end{array}$

F. Theory dependence of reality 22

III. The Two-Model Representation of Quantum Mechanics 25

A. Model of Facts and $\psi$-model $\quad 25$

B. Translation modes $\quad 27$

C. Elimination of paradoxes 28

D. Comparison with the Copenhagen dualistic world model 30

E. Bell's list of "bad words" 32

IV. Time Dependence of the Wave Function and Multiple Events

A. Two different time variations $\quad 35$

B. Questions to discuss $\quad 38$

C. Occurrence axioms for multiple events $\quad 39$

D. Historic annotations $\quad 45$

E. Different kinds of alleged $\psi$-reduction $\quad 46$

F. Further remarks $\quad 49$

V. Other Application Modes; Quasi-Properties and $\psi$-Structures

A. Modes of application $\quad 51$

B. Quasi-properties, quasi-observations $\quad 52$

C. Mutual independence of application modes 53 
D. Generalization 56

E. Spatial $\psi$-structures $\quad 56$

F. Further application modes $\quad 58$

G. Defining an "observation" 58

H. Initial values and $\psi$-preparation $\quad 59$

I. Non-factual aspects of $\psi \quad 60$

VI. General Discussion $\quad 63$

A. Critique of the Copenhagen interpretation 63

B. Answers to questions of understanding $\quad 69$

B.1. "Macroscopic" systems 69

B.2. Single objects or ensembles? $\quad 70$

$\begin{array}{ll}\text { B.3. Interaction versus measurement } & 70\end{array}$

$\begin{array}{ll}\text { B.4. Einstein's Moon } & 71\end{array}$

B.5. Atomic print 74

VII. Uncertainties and Uncertainty Relations $\quad \mathbf{7 7}$

$\begin{array}{ll}\text { A. Purpose of investigation } & 77\end{array}$

$\begin{array}{ll}\text { B. Mathematical definition } & 77\end{array}$

$\begin{array}{ll}\text { C. The Critical Interpretation } & 78\end{array}$

D. Heisenberg's interpretations $\quad 81$

E. Analysis and critique $\quad 81$

F. Hybrid models $\quad 86$

$\begin{array}{ll}\text { G. Result } & 87\end{array}$

H. On a debate between Einstein and Bohr $\quad 88$

VIII. Critical Notes on the Einstein-Podolsky-Rosen Argument 91

A. Introductory remarks $\quad 91$

B. Three definitions of reality 92

C. The intended indirect proof $\quad 97$

D. Application of the Critical Interpretation 99

E. Bell's inequalities 101

F. EPR in brief 101

$\begin{array}{ll}\text { IX. Conclusion } & 103\end{array}$

A. Deductive synopsis of the main results 103

B. Solution of the main conceptional problems 106

$\begin{array}{ll}\text { C. Questions of method } & 112\end{array}$

D. Brief summary 114

$\begin{array}{ll}\text { Acknowledgements } & 115\end{array}$

$\begin{array}{ll}\text { References } & 116\end{array}$ 